УДК 665.652.4

ПЕРСПЕКТИВА ПРИМЕНЕНИЯ ЦЕОЛИТСОДЕРЖАЩИХ

КАТАЛИЗАТОРОВ В ПРОЦЕССЕ АЛКИЛИРОВАНИЯ

\title{
PERSPECTIVE OF APPLICATION OF ZEOLITE CATALYSTS \\ IN THE PROCESS OF ALKYLATION
}

Е.Ф. Трапезникова, Т.В. Смольникова, С.Р. Хафизова, Т.В. Николаева, Р.P. Нурисламова

Уфимский государственный нефтяной технический университет, г. Уфа, Российская Федерация

\author{
E.F. Trapeznikova, T.V. Smolnikova, S.R. Khafizova, \\ T.V. Nikolaeva, R.R. Nurislamova
}

Ufa State Petroleum Technological University,

Ufa, Russian Federation

e-mail: elnik80@mail.ru

\begin{abstract}
Аннотация. В статье представлены основные аспекты развития процесса алкилирования изобутана олефинами на цеолитсодержащих катализаторах. Сущность процесса алкилирования - введение в молекулу углеводорода алкильной группы с получением сильно разветвленных парафиновых углеводородов, обладающих хорошими
\end{abstract} антидетонатационными свойствами. Алкилат удовлетворяет техническим, эксплуатационным и экологическим требованиям европейских стандартов на автомобильное топливо, поэтому для развития российской нефтепереработки увеличение производства алкилата является перспективным направлением, а задача повышения эффективности процесса алкилирования - актуальной. В качестве сырья применяются изобутановая и бутан-бутиленовые фракции, поступающие с установок 
получения метил-третбутилового эфира (МТБЭ) и каталитического крекинга.

В статье рассмотрены стадии карбокатионного механизма процесса алкилирования изобутана олефинами. Проведен сравнительный анализ процесса алкилирования на традиционных (кислотных) и цеолитсодержащих катализаторах.

Выявлено, что процесс алкилирования с использованием катализатора, основанного на цеолите, исключает токсичные и агрессивные летучие компоненты, имеет низкий уровень отходов производства, обладает высокой активностью, селективностью, стабильностью. Однако реакции циклизации, дегидрирования, сопряженной олигомеризации олефинов оказывают существенное влияние на дезактивацию твердокислотного катализатора. Главной причиной потери активности катализаторов алкилирования является образование алкилциклопентадиеновых (АЦПД) соединений.

Описаны способы уменьшения протекания побочных реакций. Установка алкилирования на основе цеолитсодержащего катализатора в настоящий момент еще не введена в российскую промышленность, но было проведено множество исследований рассматриваемого процесса как зарубежными, так и отечественными учеными. Представлены разработки технологий алкилирования на твердокислотных катализаторах ведущих зарубежных компаний. Расходы на реализацию твердокислотного алкилирования ниже, чем для сернокислотных и фтороводородных установок. Сделан вывод, что применение твердых суперкислотных катализаторов способствует улучшению технологии алкилирования.

Abstract. The main aspects of development of isobutane alkylation with olefins on zeolite catalysts are presented in the article. The essence of the alkylation process is the introduction of alkyl group into the hydrocarbon molecule to produce highly branched paraffin hydrocarbons, having good antidetonation properties. Alkylat meets the technical, operational and 
environmental requirements of European standards for automotive fuel, therefore, for the development of Russian oil refining, increasing the production of alkylate is a promising direction, and the task of increasing the efficiency of the alkylation process is topical. Isobutane and butane-butylene fractions from the methyl tert-butyl ether (MTBE) production plants and catalytic cracking are used as raw materials.

The stages of the carbocation mechanism of the alkylation of isobutane with olefins are considered in the article. A comparative analysis of the alkylation process on traditional (acidic) and zeolite catalysts is carried out.

It has been found that the alkylation process using a zeolite catalyst eliminates toxic and aggressive volatile components, has a low level of production waste, has high activity, selectivity, stability. However, the cyclization, dehydrogenation, conjugated olefin oligomerization reactions have a significant effect on the deactivation of the solid acid catalyst. The main reason for the loss of activity of alkylation catalysts is the formation of alkylcyclopentadiene (ACPD) compounds.

Methods for reducing the course of adverse reactions are described. An alkylation unit based on a zeolite catalyst has not already been introduced into Russian industry, but a lot of research has been done on this process by both foreign and domestic scientists. The development of alkylation technologies on solid-acid catalysts of leading foreign companies is presented. The costs for the realization of solid-acid alkylation are lower than for sulfuric and hydrofluoric plants. It is concluded that the use of solid superacid catalysts contributes to the improvement of alkylation technology.

Ключевые слова: активный центр, алкилат, алкилирование, бутанбутиленовая фракция, гетерогенный катализатор, деалкилирование, дезактивация, изоалкан, изобутан, кокс, крекинг, октановое число, олефины, олигомеризация, регенерация, цеолит. 
Key words: active center, alkylate, alkylation, butane-butylene fraction, heterogeneous catalyst, dealkylation, deactivation, isoalkane, isobutene, coke, cracking, octane number, olefins, oligomerization, regeneration, zeolite.

Потребность материального производства и развитие общества послужили источником формирования и совершенствования науки. Открытие ранее неизвестных свойств материалов, способов их обработки, энергетических источников дают толчок появлению современных направлений производства и потребления.

За последнее время число городов, которые подвержены высокому и всевозрастающему воздействию загрязняющих веществ в атмосфере, увеличивается по всем показателям загрязнения воздуха.

Постоянно расширяющийся парк автомобилей в стране привел к тому, что основная доля вредных выбросов в окружающую среду крупных городов приходится на автотранспорт.

Наиболее токсичные выбросы автомобилей: оксид углерода, окислы азота, сажа, альдегиды, диоксид серы и соединения свинца. Наибольшую опасность из всех токсичных веществ для человека представляют соединения свинца, марганца и железа, которые влияют на кровеносную, нервную системы, вызывают цирроз печени. Свинец откладывается в костях и других тканях человека [1].

Одним из наиболее эффективных способов снижения количества вредных выбросов автотранспорта является поэтапный переход на применение автотранспортных средств и топлив, которые отвечают более жестким экологическим нормативам (Евро 4, 5 и другие) [2].

Наряду с экологичностью стоит задача получения высокооктановых бензинов с низким содержанием ароматики. Благодаря высокооктановым добавкам повышается мощность карбюраторных двигателей, снижается удельный расход потребляемого топлива. 
По показателям качества алкилат является лидером среди других высокооктановых добавок, так как он не содержит ароматических и серосодержащих соединений. Очевидно, что для развития российской нефтепереработки перспективным направлением является увеличение производства алкилата, а задача повышения эффективности процесса алкилирования - актуальной [3].

Сущность процесса алкилирования - введение в молекулу углеводорода алкильной группы с получением сильно разветвленных парафиновых углеводородов, которые обладают хорошими антидетонатационными свойствами.

В 1932 году была установлена возможность каталитического алкилирования парафинов алкенами на безводном хлориде алюминия, промотированным хлороводородом [4]. В 1938 году была выявлена высокая результативность использования концентрированной $\mathrm{H}_{2} \mathrm{SO}_{4}$ как катализатора алкилирования метилпропана олефинами [5].

Впервые установка сернокислотного алкилирования начала эксплуатироваться в конце 30-х годов, а несколькими годами позже фтористоводородного. Предварительно целевым продуктом был исключительно компонент авиабензина, но в послевоенный период на основе газов каталитического крекинга алкилирование нашло применение в улучшении моторных качеств товарных автобензинов [6].

Бензины-алкилаты состоят из разветвленных алканов, обладают высоким октановым числом $[7,8]$, не содержат аренов, алкенов и серы, не токсичны и имеют низкое давление насыщенных паров.

В технологически развитых странах алкилат достигает $13 \%$ в высокооктановых автомобильных бензинах и является основным компонентом в авиационных бензинах. Объемы зарубежного производства алкилата превышают 70 млн т/год, а в России достигают не более 0,5 млн т/год. На предприятиях России эксплуатируются пять установок 
сернокислотного алкилирования: в Омске, Уфе, Ярославле, Самаре и Рязани [9].

Установка алкилирования на основе цеолитсодержащего катализатора в настоящий момент еще не введена в российскую промышленность, но, согласно данным патентной документации [10], было проведено множество исследований рассматриваемого процесса как зарубежными, так и отечественными учеными.

Необходимость в оборудовании для снижения активности кислоты, аппаратах для промывки продукта и емкостей для хранения свежей и отработанной кислот, токсичность, высокий удельный расход, коррозионная активность, протекание побочных реакций в результате быстрого растворения олефиновых углеводородов в кислой фазе являются существенными недостатками данных катализаторов [11]. В связи с этим разработка новых гетерогенных катализаторов алкилирования, основанных на цеолитах, является одной из наиболее актуальных задач совершенствования современных промышленных процессов алкилирования.

Согласно литературным данным, высокоперспективными гетерогенными катализаторами алкилирования изобутана олефинами являются:

- каталитические системы, имеющие в своем составе цеолиты, модифицированные благородными или переходными металлами;

- каталитические системы с содержанием цеолита типа фожазит в редкоземельной форме.

В качестве сырья применяется изобутановая фракция, которая вырабатывается на газофракционирующих установках каталитического крекинга, а также предварительно очищенная от кислородсодержащих соединений, следов мышьяка, ртути и соединений серы бутан-бутиленовая фракция, поступающая с установок получения метил-третбутилового эфира (МТБЭ) и каталитического крекинга. 
Процесс алкилирования на цеолитсодержащем катализаторе протекает по карбокатионному механизму, включающему следующие стадии:

- инициирование - образование карбениевых ионов;

- алкилирование - взаимодействие карбениевых ионов с олефином;

- изомеризация карбениевых ионов;

- обрыв цепи - перенос гидрид-аниона с изопарафина на карбениевый ион;

- полимеризация - взаимодействие карбениевых ионов с олефинами с образованием тяжелых продуктов и кокса;

- деалкилирование и крекинг.

Повышенные температуры процесса способствуют протеканию реакции деалкилирования и крекинга с высокими скоростями. В результате этих реакции образуется широкая фракция алкилата.

Для получения алкилата с высоким октановым числом и выходом необходимо:

- увеличить скорость процессов гидридного переноса;

- уменьшить скорости полимеризации олефинов, деалкилирования и крекинга продуктов;

- сократить протекание процессов коксообразования.

Для того чтобы достичь этих целей, процесс алкилирования ведут при малом времени контакта олефина с катализатором, низкой температуре и в избытке изоалканов.

Для катализаторов, основанных на цеолитах, характерны высокая активность, селективность, стабильность, определенная микропористая структура, способность к регенерации. Это доказывает, что твердые кислотные катализаторы являются более эффективными в применении. Однако в ходе побочных реакции образуются высокомолекулярные углеводороды $[12,13]$, которые блокируют пористую структуру и поверхностные активные центры твердокислотного катализатора, что ограничивает их употребление в процессе алкилирования [14]. 
В процессе алкилирования изобутана олефинами протекает конкурирующая реакция сопряженной олигомеризации олефинов при взаимодействии с кислотными центрами катализатора [15], которая оказывает существенное влияние на его дезактивацию. Также на дезактивацию твердокислотного катализатора влияют реакции циклизации и дегидрирования [16]. Циклические ионы имеют длительный срок службы на поверхности катализатора, что способствует росту еще более крупных молекул. Кокс может дезактивировать катализатор путем загрязнения или закупорки пор [17-20]. До полного закупоривания пор молекулы кокса могут уменьшаться до диаметра цеолитных пор, увеличивая сопротивление диффузии $[21,22]$.

Главной причиной потери активности катализаторов алкилирования является образование алкилциклопентадиеновых (АЦПД) соединений. Кислотные центры поверхности твердых катализаторов ослабевают при воздействии сформировавшихся устойчивых циклопентильных катионов, а это, в свою очередь, приводит к невозможности осуществления гидридного переноса изобутана, что исключает ход основных реакций алкилирования.

Уменьшение срока службы цеолитных катализаторов связано с применением традиционных методов регенерации (высокотемпературное окисление), которые изменяют морфологию, поверхность и пористость катализатора [23].

В процессе алкилирования изобутана олефинами возможны реакции полимеризации олефинов, в результате которых образуются более тяжелые продукты и кокс.

Протеканию побочных реакций способствует увеличение температуры, поэтому необходимо осуществлять реакцию при возможно пониженной температуре, обеспечивающей при этом достаточную скорость процесса. Избыток циркулирующего изобутана в системе предотвращает реакции полимеризации олефинов и деалкилирования. 
Потребность в высокооктановых бензинах, жесткие экологические требования ряда стран привели к разработке ведущими зарубежными компаниями технологий алкилирования на твердокислотных катализаторах.

\section{Процесс алкилирования Fixed-Bed-Alkylation (FBA)}

\section{компании Haldor Topsoe A/S}

Процесс FBA представляет собой совокупность положительных качеств жидких катализаторов и системы реакторов с неподвижным слоем катализатора [24-26]. На рисунке 1 представлена блок-схема установки алкилирования компании Haldor Topsoe A/S.

Пропан

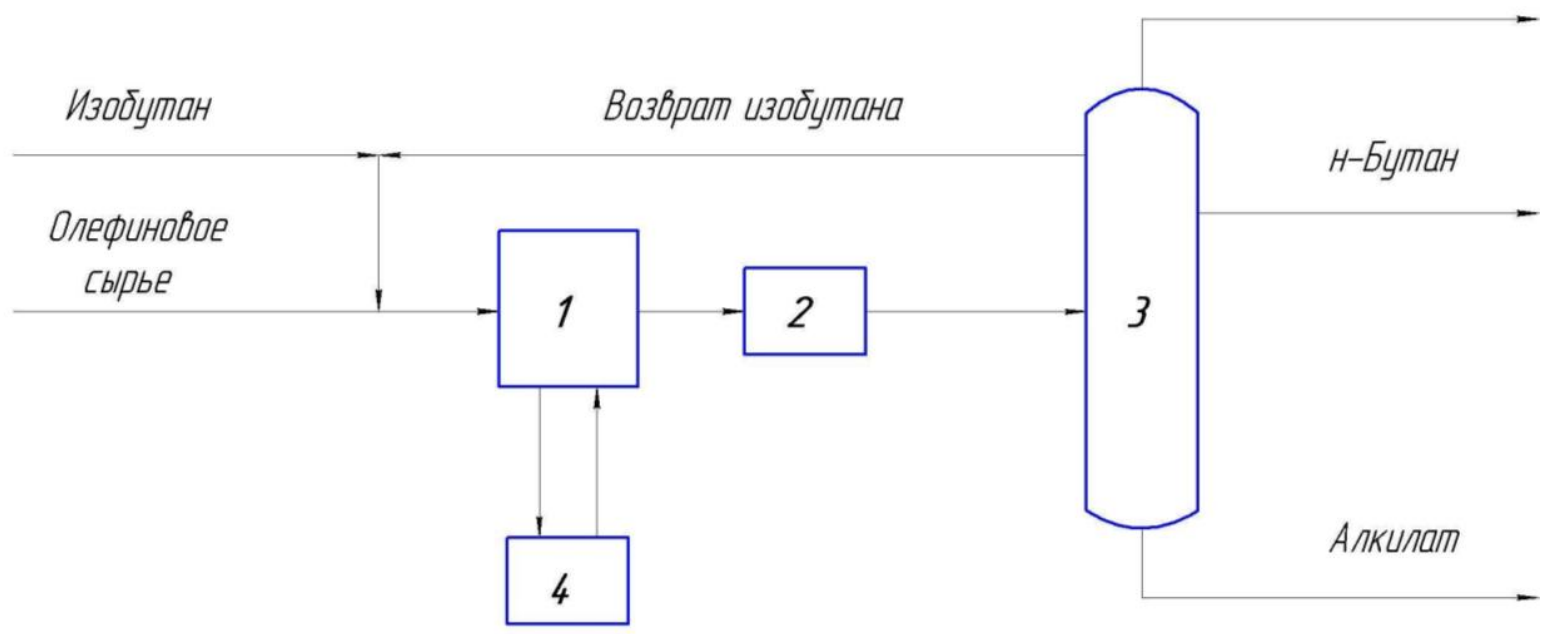

1 - реактор; 2 - узел очистки;

3 - фракционирующая секция; 4 - секция регенерации

Рисунок 1 - Блок-схема установки алкилирования компании Haldor Topsoe A/S

Сырье, состоящее из олефинов и изобутана, смешивается с рециркулирующим изобутаном и подается в реакторный блок (1). На катализаторе (сверхкислота, адсорбированная на пористом носителе) происходит полное превращение олефинов. Наблюдение за катализатором, 
поддержание его активности возможно вследствие простоты конструкции реакторной системы с неподвижным слоем.

Продукты, полученные в ходе процесса, содержат остатки растворенной кислоты, от которых избавляются в узле очистки (2). В блоке фракционирования (3) очищенные от кислоты продукты реакции разделяются на пропан, изобутан, н-бутан и алкилат. Особая конструкция реактора позволяет селективно выводить из него небольшие количества дезактивированного катализатора. Этот кислотный катализатор направляется в секцию регенерации (4) для восстановления активности. Отличительной чертой процесса $F B A$ является встроенная и относительно недорогая технология, позволяющая поддерживать активность катализатора в течение процесса. Также преимуществами процесса $F B A$ являются: высокое октановое число получаемого алкилата (таблица 1), гибкость по сырью и рабочей температуре, небольшой расход катализатора и невысокие эксплуатационные затраты.

Таблица 1. Октановое число алкилата, получаемого в процессе компании Haldor Topsoe $A / S$

\begin{tabular}{|c|c|c|c|}
\hline Сырье & $\begin{array}{c}\text { Рафинат после } \\
\text { синтеза МТБЭ }\end{array}$ & $\begin{array}{c}\text { Фракция } \mathrm{C}_{4} \\
\text { с установки ККФ }\end{array}$ & $\begin{array}{c}\text { Фракция } \mathrm{C}_{3^{-}} \\
\mathrm{C}_{6}\end{array}$ \\
\hline Октановое число алкилат, ед. & & & 95 \\
ИМ & 98 & 95 & 93 \\
ММ & 95 & 92 & 91 \\
\hline
\end{tabular}

Процесс алкилирования AlkyClean компаний ABB Lummus Global, Albemarle Catalysts и Neste Oil

Технология процесса алкилирования с использованием нового цеолитного катализатора (цеолит USY) лишена недостатков, которые характерны для жидких катализаторов (серной и плавиковой кислот). Твердокислотный катализатор не содержит галогенов, а его кислотность вызвана наличием в его структуре кислотных центров без нанесения жидких кислот на его поверхность. В результате процесса не образуются 
отработанная кислота и кислый гудрон, а получающиеся продукты не требуют специальной доочистки. В ходе процесса не используются токсичные, коррозирующие оборудование кислоты, что значительно упрощает эксплуатацию установки, повышает безопасность обслуживающего персонала, не оказывает отрицательного влияния на окружающую среду. Блок-схема установки алкилирования компании $A B B$ Lummus Global/Akzo Nobel/Fortum Oil \& Gas представлена на рисунке 2.

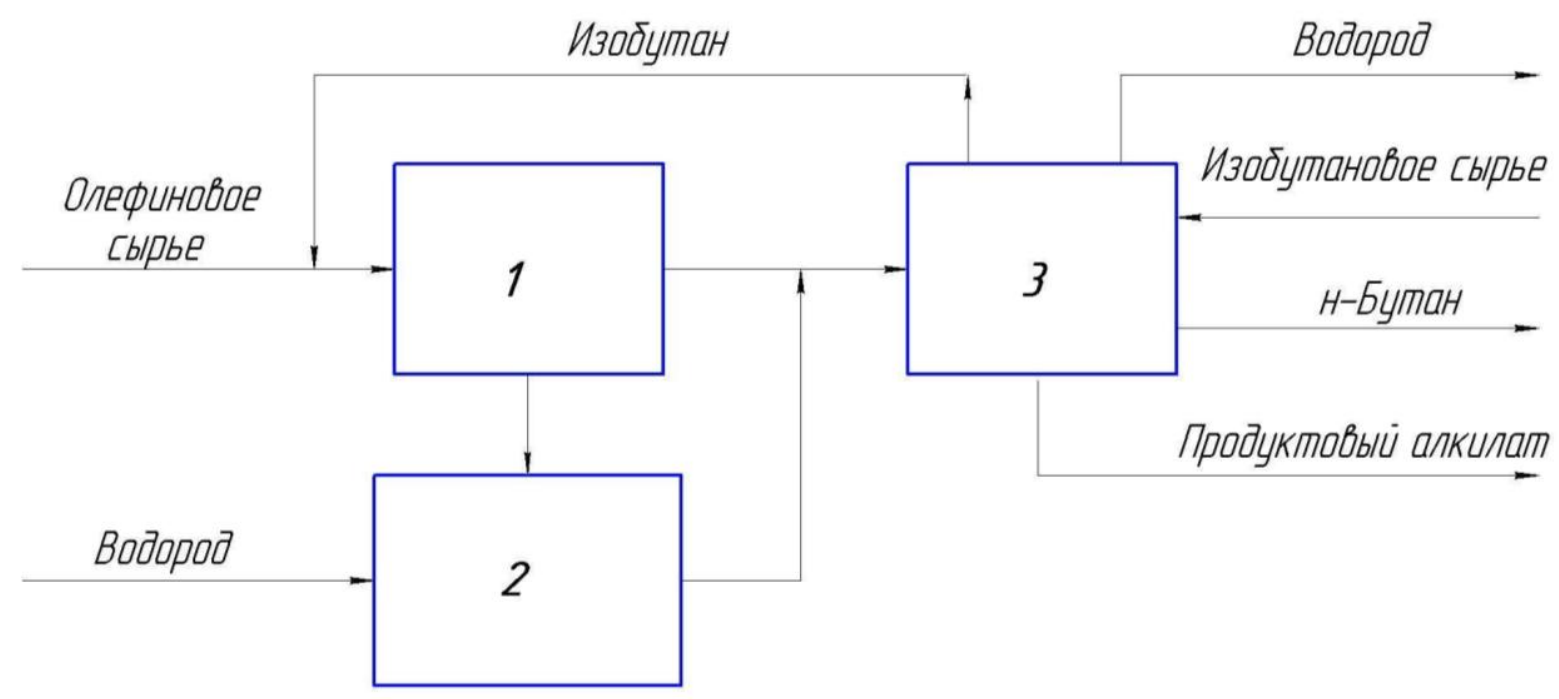

1,2 - реакторы; 3 - фракционирующая секция

Рисунок 2. Блок-схема установки алкилирования компании ABB Lummus Global/Akzo Nobel/Fortum Oil \& Gas

Легкие олефины, смешиваясь со свежим и рециркулирующим изобутаном, поступают в реакторы алкилирования с твердокислотным катализатором (1), в которых протекает процесс алкилирования. Применяемый катализатор исключает опасность для работников установки и окружающей среды, характерную для технологий, использующих традиционные жидкие катализаторы. Одновременно с процессом алкилирования в реакторе происходит мягкая жидкофазная регенерация катализатора изобутаном и водородом. Реактор продувают водородом в паровой фазе при высокой температуре (2). Получившиеся продукты реакции и мягкой регенерации направляются в секцию 
фракционирования (3). В результате фракционирования получают н-бутан, алкилат, рециркулирующий изобутан и извлекают водород, который используется на других гидрогенизационных процессах нефтеперерабатывающего завода (НП3). Процесс AlkyClean не образует масел, которые растворяются в кислотах, а продукты процесса не требуют доочистки.

Высокое качество полученного алкилата доказывает, что процесс AlkyClean является эффективным. Данная технология имеет низкую чувствительность к виду перерабатываемого сырья и устойчива к примесям.

Создатели технологии, проанализировав затраты, необходимые для строительства установки процесса AlkyClean, убедились в том, что эти затраты на 10-15\% ниже затрат, необходимых на постройку установки алкилирования, использующей в качестве катализатора серную кислоту, и приблизительно равны затратам, которые необходимы для строительства установки алкилирования, использующей фтороводородную кислоту. Затраты, необходимые для эксплуатации установки процесса AlkyClean, сопоставимы с эксплуатационными затратами алкилирования серной кислотой. Для обеих технологий характерен высокий расход катализатора, что вносит значительный вклад в издержки, но для процесса AlkyClean эти затраты меньше, так как катализатор эксплуатируется в течение большего времени. По сравнению с процессами AlkyClean и алкилирования, использующие $\mathrm{H}_{2} \mathrm{SO}_{4}$, установки, эксплуатирующие $\mathrm{HF}$, более дешевы. Однако такие установки имеют высокие затраты на монтаж оборудования, контроля производства.

\section{Процесс алкилирования ExSact компании Exelus}

Процесс по технологии ExSact основан на проведении алкилирования с последующей регенерацией катализатора [27-30]. Процесс проводится в двух реакторах с неподвижным слоем катализатора (на рисунке 3 показан 
один реактор). В одном реакторе - алкилирование, а во втором регенерация катализатора, то есть реакторы работают по очереди. За счет этого обеспечивается непрерывность процесса, что приводит к снижению капитальных затрат.

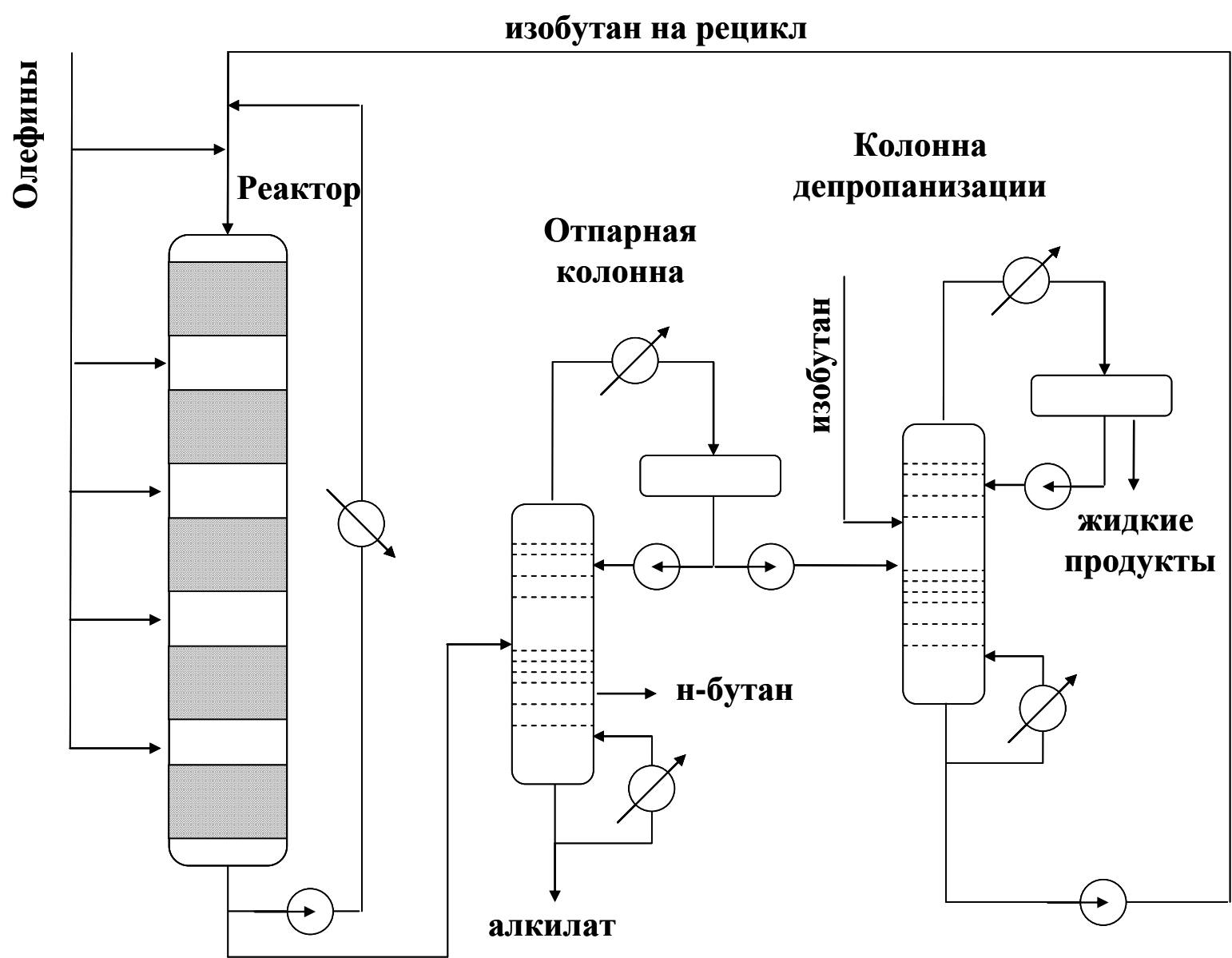

Рисунок 3. Принципиальная технологическая схема установки алкилирования ExSact

Олефины смешиваются с изобутаном, который возвращается из секции фракционирования, и с рециркулирующим реакционным потоком перед подачей в реактор. Реакционная смесь направляется в первый многоступенчатый с неподвижным слоем катализатора реактор, где протекают реакции алкилирования, одновременно во втором реакторе происходит регенерация катализатора. Катализатор не чувствителен к малым изменениям температуры. Реакции алкилирования являются экзотермическими, поэтому для отвода тепла используется теплообменник. 
Регенерация катализатора проводится при повышенной температуре $\left(250{ }^{\circ} \mathrm{C}\right)$ с использованием контура циркуляции смеси водород/углеводород. Катализатор не требует оборудования для нейтрализации или промывки полученного алкилата перед последующей обработкой. Нет необходимости применять коррозионностойкие материалы. Для данной технологической схемы характерны низкие капитальные затраты.

Для упрощения работы реактора цикл алкилирования рассчитан на $12-24$ ч. После цикла алкилирования реактор отключают и регенерируют, в то время как второй реактор поддерживает постоянство производства алкилата. В ходе процесса расход водорода остается минимальным вследствие малой закоксованности поверхности катализатора. В течение процесса катализатор сохраняет высокую селективность и позволяет получать продукт с высоким выходом.

Такие каталитические характеристики были достигнуты благодаря оптимизации силы кислотных центров, их расположения и плотности, а также организации его пористой структуры на различных уровнях:

- «зона диспергирования» на внешней поверхности слоя катализатора препятствует повышенной адсорбции олефинов, что снижает их олигомеризацию;

- на макроуровне «реакционная зона» состоит из частиц катализатора определенной формы, интенсифицирующие процессы массопереноса;

- мезоструктура катализатора препятствует образованию кокса, что снижает скорость его дезактивации;

- наноуровень катализатора интенсифицирует процессы алкилирования за счет оптимизации силы и распределения кислотных центров. 


\section{Процесс алкилирования Alkylene компании UOP}

В 1990-х годах компания UOP разработала технологию алкилирования Alkylene [31].

Использование твердокислотных катализаторов в процессе алкилирования показало, что такие системы обладают высокой активностью, селективностью, однако стабильность их работы низка порядка нескольких часов. Разработанные катализаторы с нанесенной на поверхность кислотой не получили промышленного применения, так как регенерация подобных катализаторов осложнена отжигом кокса.

Компания UOP создала новый катализатор $H A L-100$, в котором используется система $\mathrm{AlCl}_{3} / \mathrm{Al}_{2} \mathrm{O}_{3}$, модифицированная катионами калия и нанесенным металлом VIII группы (Pt, Pd или Ni). Данный катализатор имеет высокую активность, стабильность, селективность, а его регенерация не требует отжига кокса. Качество получаемых продуктов сопоставимо с качеством алкилата, полученного при алкилировании с использованием традиционных минеральных кислот.

Схема процесса представлена на рисунке 4. Олефины вступают в реакцию с изобутаном на поверхности катализатора $H A L-100$, при этом образуется алкилат. Основным компонентом алкилата являются разветвленные триметилпентаны (ТМП), имеющие высокое октановое число порядка 100, диметилгексаны (ДМГ), имеющие более низкое октановое число.

В результате реакций полимеризации, протекающих в присутствии жидких кислотных катализаторов, образуется кислый гудрон, что увеличивает расход катализатора и снижается выход алкилата. В процессе Alkylene реакции полимеризации имеют низкую эффективность, кислый гудрон не образуется, а алкилат имеет более высокую температуру кипения по сравнению с продуктами, получаемыми при использовании серной или плавиковой кислот. 
Легкие фракции

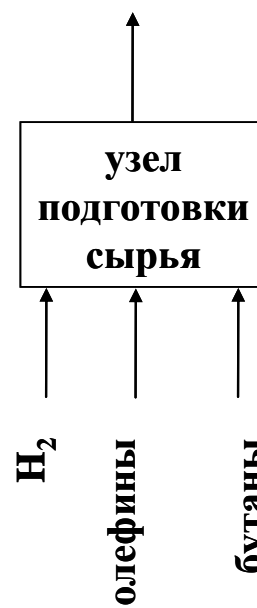

Легкие фракции

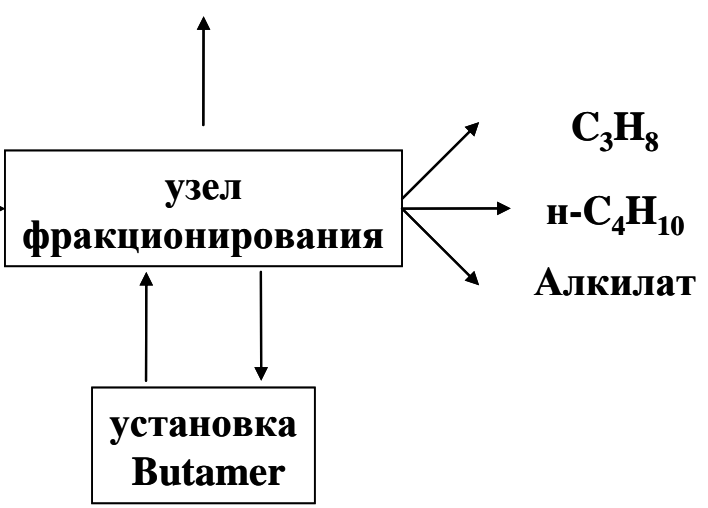

Рисунок 4. Упрощенная блок-схема процесса Alkylene UOP

Высокий выход триметилпентанов в процессе Alkylene достигается за счет проведения процесса при:

- низких температурах;

- высоком локальном соотношении изобутан/олефин;

- малом времени контакта реагентов с катализатором.

Краткосрочный и тесный контакт углеводородов с катализатором в процессе Alkylene позволят получить продукт с высоким октановым числом и выходом. Вторичные процессы сводятся к минимуму за счет эффективного отделения алкилата от катализатора. Образующийся алкилат в процессе Alkylene не уступает по качеству алкилату, полученному в процессах с использованием жидкокислотных катализаторов, и не имеет в своем составе кислого гудрона. По своей природе катализатор схож с каталитическими системами, используемыми в гидрогенизационных процессах. Оборудование не требует дорогих сплавов, так как процесс ведется в мягких условиях.

На рисунке 5 представлена схема узлов алкилирования и ректификации. Олефиновое и изобутановое сырье смешивается и вводится в лифт-реактор из углеродистой стали, в который также непрерывно подается регенерированный катализатор, что необходимо для поддержания постоянства активности катализатора и уменьшения его расхода. В 
результате процесса увеличиваются качество и выход продукта, его эффективность.

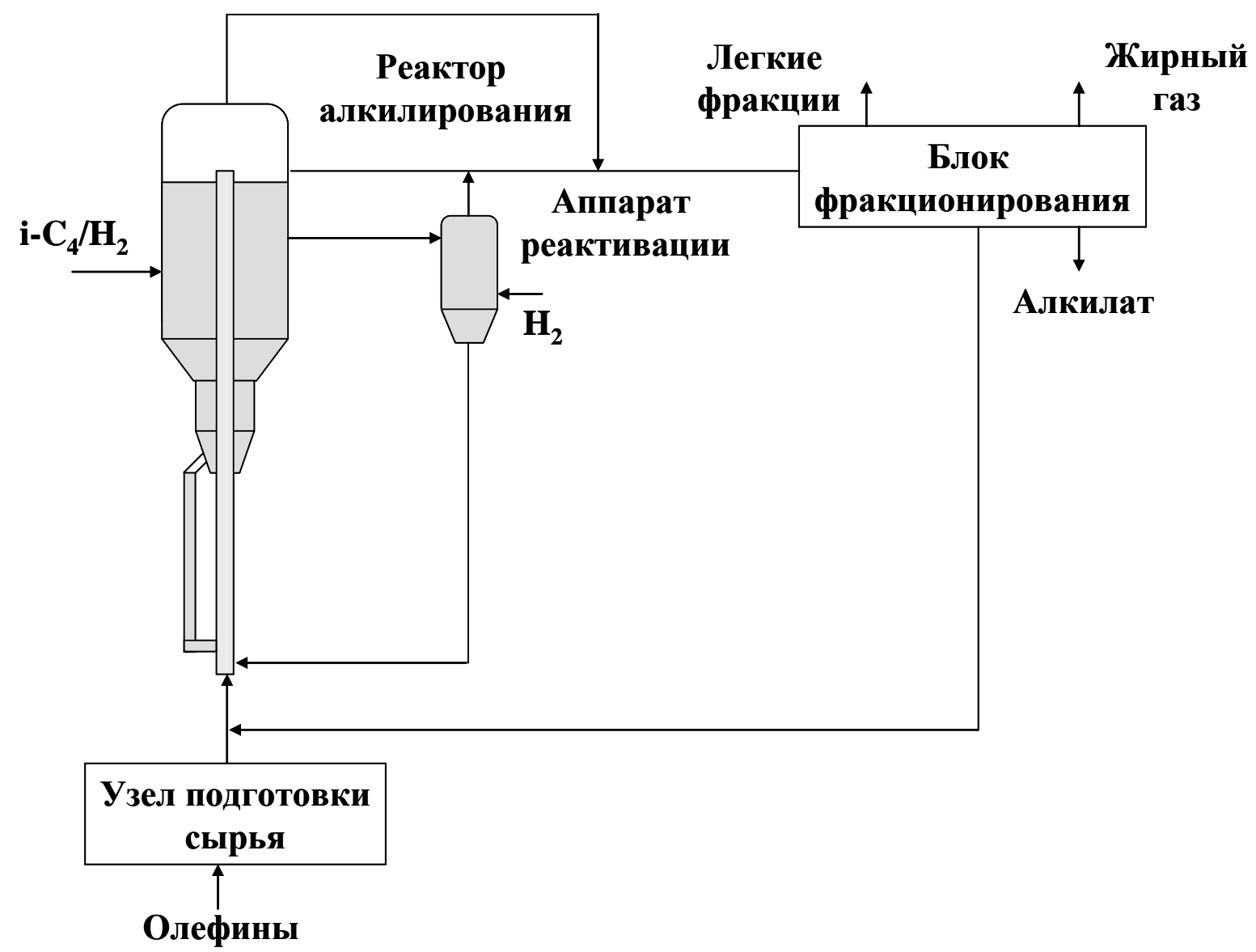

Рисунок 5. Схема узла алкилирования процесса Alkylene

В реакторе жидкая углеводородная фаза перемещает катализатор с меньшей скоростью по сравнению с другими процессами с подвижным слоем катализатора. Время, достаточное для завершения первичных процессов и уменьшения вторичных, составляет несколько минут. В реакционной зоне происходит эффективное перемешивание катализатора и углеводородов, а в верхней части реактора происходит отделение углеводородов от частиц катализатора. Регенерация катализатора осуществляется гидрированием на его поверхности алкилата, в результате чего активность катализатора становится близкой к активности свежего образца. Небольшое количество алкилата на поверхности катализатора $H A L-100$ позволяет проводить регенерацию при малом расходе водорода. 
Преимуществом процесса Alkylene перед другими процессами с движущимся слоем является малый износ оборудования и катализатора благодаря эффекту «смазывания» жидкой фазой. Расход катализатора уменьшается за счет низкой скорости циркулирующей суспензии, часть потока которой подается на регенерацию в газовой фазе, которая проводится в более жестких условиях, для извлечения оставшихся следов тяжелых продуктов и восстановления активности катализатора.

Подобно узлу ректификации, используемый для отделения продуктов алкилирования в присутствии жидких минеральных кислот алкилат процесса Alkylene направляется в блок фракционирования.

Компанией UOP был разработан процесс Butamer, превращающий н-бутан в изобутан с высокой селективностью, стабильностью работы катализатора и малым расходом водорода. При совместном протекании процессов Butamer и Alkylene достигается то, что н-бутан, содержащийся в сырье, полностью превращается в изобутан, тем самым исключается проблема нехватки насыщенных углеводородов в процессе алкилирования, а расход ресурсов уменьшается. Исходя из этого, была предложена новая технологическая схема, объединяющая процессы Butamer и Alkylene (рисунок 4). Оборудование для фракционирования и предварительной обработки сырья является идентичным для обоих процессов. Совместная деятельность двух технологий снижает капиталовложения, необходимые для строительства отдельной установки Butamer, и снижает затраты на ее эксплуатацию.

Высокий выход алкилата, отсутствие кислого гудрона являются преимуществами процесса Alkylene перед технологиями алкилирования, использующими жидкие минеральные кислоты. Капитальные затраты технологии Alkylene несколько выше, а затраты на эксплуатацию ниже технологии алкилирования в присутствии серной кислоты. Использование плавиковой кислотой требует больших капитальных и эксплуатационных 
затрат. Таким образом, можно сделать вывод о безопасности и конкурентоспособности процесса Alkylene.

\section{Вывод}

Последние 15-20 лет стали решающими в эволюции твердых катализаторов алкилирования. В процессе алкилирования появилось большое количество новых технологий, развивающих отечественную и зарубежную нефтепереработку.

Перспективным направлением в развитии производства алкилбензина на твердокислотных катализаторах является применение цеолитов, что исключает токсичные и агрессивные летучие компоненты, имеет низкий уровень отходов производства, обладает высокой активностью, селективностью, стабильностью, протекает с отсутствием побочных нефтепродуктов. В связи с этим такие зарубежные компании, как Haldor Topsoe A/S (процесс Fixed-Bed-Alkylation), ABB Lummus Global, Albemarle Catalysts u Neste Oil (процесс AlkyClean), Exelus (процесс ExSact), UOP (процесс Alkylene) разрабатывали технологии алкилирования, альтернативные жидкокислотным процессам. Алкилат, получаемый в ходе процесса с использованием твердых катализаторов, не уступает по качеству алкилату, полученному при алкилировании в присутствии жидких кислот. Расходы на реализацию твердокислотного алкилирования ниже, чем для сернокислотных и фтороводородных установок.

Оптимизация кислотных и структурных характеристик, разработка эффективных методов регенерации твердокислотных катализаторов алкилирования доказывают, что твердые системы по своим свойствам не уступают жидким кислотам.

Таким образом, цеолитные катализаторы благодаря своим техникоэкономическим показателям могут быть конкурентоспособными с такими традиционными промышленными катализаторами, как серная и плавиковая кислоты. 


\section{Список использованных источников}

1. Звягинцев А.А., Прохорова Е.В. Влияние качества автомобильного бензина на экологию // Современные автомобильные материалы и технологии. М.-Курск, 2016. С. 122-127.

2. Шириязданов P.P. Исследование закономерностей получения и применения цеолитсодержащих катализаторов алкилирования изобутана олефинами: дис. ... канд. техн. наук. Уфа: УГНТУ, 2011. 145 с.

3. Щербакова Ю.А., Линов А.И., Короленко М.В., Ивашкина Е.Н. Этапы математического моделирования процесса алкилирования изобутана олефинами // Секция 11. Современные технологии подготовки освоения и переработки минерального и углеводородного сырья. Подсекция 2. Моделирование процессов переработки углеводородного сырья. Томск, 2013. С. 159-160.

4. Ipatieff V.N., Grosse A.V. Reaction of Paraffins with Olefins // J. Am. Chem. Soc. 1935. Vol. 57. 1616 p.

5. Суханов В.П. Каталитические процессы в нефтепереработке. М.: Химия, 1979. 344 с.

6. Шураев М.В., Крымкин Н.Ю., Шакун В.А. Алкилирование изобутана олефинами в равновесных условиях // Известия Самарского научного центра Российской академии наук. 2011. № 4-4. С. 1178-1182.

7. Солодова Н.Л., Абдуллин А.И., Емельянычева Е.А. Алкилирование изопарафинов олефинами // Вестник Казанского технологического университета. 2013. № 18. С. 254-258.

8. Ахметов С.А. Технологии глубокой переработки нефти и газа. Уфа: Гилем, 2002. 480 с.

9. Аналитический портал химической промышленности [Электронный pecypc]. URL: //http://www.newchemistry.ru (дата обращения: 15.03.2018).

10. Шириязданов Р.Р. Суперкислотные цеолитные каталитические системы для алкилирования изобутана олефинами // Ползуновский вестник. 2010. № 3. С. 121-126. 
11. Дорогочийский А.З., Лютер А.В., Вольпова Е.Г. Сернокислотное алкилирование изопарафинов олефинами. М.: Наука, 1970. 216 с.

12. Лавренов А.В., Богданец Е.Н., Дуплякин В.К. Катализ в промышленности. 2009. № 1. С. 28.

13. Querini C.A., Roa E. Deactivation of Solid Acid Catalysts During Isobutane Alkylation with $\mathrm{C}_{4}$ Olefins // Appl. Catal. A: Gen. 1997. V. 163. P. 199.

14. Шураев М.В., Крымкин Н.Ю., Шакун В.А. Алкилирование изобутана бутиленом в равновесных условиях // Известия Самарского научного центра Российской академии наук. 2011. Т. 13. № 4 (4). C. $1178-1182$.

15. Zhang W., Sun Ì., Prins R. // The Journal of Physical Chemistry A. 2002. Vol. 106. 11805 p.

16. Pater J., Gardona F., Canaff C., Gnop N.S., Szabo G., Guisnet M. Alkylation of Isobutane with 2-Betene over HFAU Zeolite // Composition of Coke and Deactivation Effect. Industrial and Engineering Chemistry. 1999. No. 38. P. 3822-3829.

17. Froment G.F. // Stud. Surf. Sci. Catal. 1980. No. 6. P. 1.

18. Reyniers M.-F., Beirnaert H., Marin G.B. Influence of Coke Formation on the Conversion of Hydrocarbons I. Alkanes on a USY-Zeolite // Appl. Catal. A-Gen. 2000. No. 202 (1). P. 49-63.

19. Reyniers M.-F., Tang Y., Marin G.B. // Appl. Catal. A-Gen. 2000. No. 2. P. 65 .

20. Guisnet M., Magnoux P., Martin D. // Stud. Surf. Sci. Catal. 1997. No. 111. P. 1.

21. Hopkins P.D., Miller J.T., Meyers B.L., Ray G.J., Roginski R.T., Kuehne M.A., Kung H.H. // Appl. Catal. A-Gen. 1996. No. 136. P. 29.

22. Williams B.A., Babitz S.M., Miller J.T., Snurr R.Q., Kung H.H. // Appl. Catal. A-Gen. 1999. No. 177. P. 161. 
23. Миначев Х.М., Мортиков Е.С., Зеньковский С.М., Мостовой Н.В., Кононов Н.Ф. Алкилирование. Исследование и промышленное оформление процесса. М.: Химия, 1982. С. 81-86.

24. Raseev S. Thermal and Catalytic Processes in Petroleum Refining. Marcel Dekker, NewYork, 2003. 920 p.

25. Hommeltoft S.I., Topsoe H.F.A. Alkylation Process. Пат. США. № 5245100.1993.

26. Hommeltoft S.I., Topsoe H.F.A. Alkylation Process. Пат. США. № 5675053. 1997.

27. Mukherjee M., Nehlsen J. Reduce Alkylate Costs with Solid-Acid Catalysts // Hydrocarbon Processing. 2007.

28. Mukherjee M., Nehlsen J., Sundaresan S. Scale-Up Strategy Applied to Solid-Acid Alkylation Process // Oil and Gas J. 2006. No. 26. Vol. 104.

29. Mukherjee M., Nehlsen J., Dixon J., Suciu G.D. Step-Out Paraffin Alkylation Process Using Engineered Solid Catalyst // Hydrocarbon World. 2008. No. 1. Vol. 3.

30. Agrawal A., Balasubramanian K. Consider Catalyst Developments for Alkylation Production // Hydrocarbon Processing. 2006.

31. Roeseler C.M., Black S.M., Shields D.J., Gosling C.D. Improved Solid Catalyst Alkylation Technology for Clean Fuels // The Alkylene Process. NPRA Annual Meeting. San Antonio, USA, 2002.

\section{References}

1. Zvyagintsev A.A., Prokhorova E.V. Vliyanie kachestva avtomobil'nogo benzina na ekologiyu [Influence of Quality of Automobile Gasoline on Ecology]. Sovremennye avtomobil'nye materialy $i$ tekhnologii - Modern Automotive Materials and Technologies. Moscow-Kursk, 2016, pp. 122-127. [in Russian]. 
2. Shiriyazdanov R.R. Issledovanie zakonomernostei polucheniya $i$ primeneniya tseolitsoderzhashchikh katalizatorov alkilirovaniya izobutana olefinami: dis. kand. tekhn. nauk [Study of the Regularities of Obtaining and Using Zeolite-Containing Catalysts for the Alkylation of Isobutane with Olefins: Cand. Engin. Sci. Dis.]. Ufa, UGNTU, 2011. 145 p. [in Russian].

3. Shcherbakova Yu.A., Linov A.I., Korolenko M.V., Ivashkina E.N. Etapy matematicheskogo modelirovaniya protsessa alkilirovaniya izobutana olefinami [Stages of Mathematical Modeling of the Process of Alkylation of Isobutane with Olefins]. Sektsiya 11. Sovremennye tekhnologii podgotovki osvoeniya $i$ pererabotki mineral'nogo $i$ uglevodorodnogo syr'ya. Podsektsiya 2. Modelirovanie protsessov pererabotki uglevodorodnogo syr'ya [Section 11. Modern Technologies for the Preparation and Development of Mineral and Hydrocarbon Raw Materials. Subsection 2. Modeling of Hydrocarbon Processing Processes]. Tomsk, 2013, pp. 159-160. [in Russian].

4. Ipatieff V.N., Grosse A.V. Reaction of Paraffins with Olefins. J. Am. Chem. Soc., 1935, Vol. 57, 1616 p.

5. Sukhanov V.P. Kataliticheskie protsessy v neftepererabotke [Catalytic Processes in Oil Refining]. Moscow, Khimiya Publ., 1979. 344 p. [in Russian].

6. Shuraev M.V., Krymkin N.Yu., Shakun V.A. Alkilirovanie izobutana olefinami v ravnovesnykh usloviyakh [Alkylation of Isobutane with Olefins under Equilibrium Conditions]. Izvestiya Samarskogo nauchnogo tsentra Rossiiskoi akademii nauk - Herald of Samara Scientific Center of Russian Academy of Sciences, 2011, No. 4-4, pp. 1178-1182. [in Russian].

7. Solodova N.L., Abdullin A.I., Emel'yanycheva E.A. Alkilirovanie izoparafinov olefinami [Alkylation of Isoparaffins with Olefins]. Vestnik Kazanskogo tekhnologicheskogo universiteta - Bulletin of Kazan Technological University, 2013, No. 18, pp. 254-258. [in Russian].

8. Akhmetov S.A. Tekhnologii glubokoi pererabotki nefti $i$ gaza [Technologies of Deep Oil and Gas Processing]. Ufa, Gilem Publ., 2002. 480 p. [in Russian]. 
9. Analiticheskii portal khimicheskoi promyshlennosti [Analytical Portal of the Chemical Industry]. [Electronic Resource]. URL: http://www.newchemistry.ru (accessed 15.03.2018). [in Russian].

10. Shiriyazdanov R.R. Superkislotnye tseolitnye kataliticheskie sistemy dlya alkilirovaniya izobutana olefinami [Superacid Zeolite Catalyst Systems for the Alkylation of Isobutane with Olefins]. Polzunovsky vestnik, 2010, No. 3, pp. 121-126. [in Russian].

11. Dorogochiiskii A.Z., Lyuter A.V., Vol'pova E.G. Sernokislotnoe alkilirovanie izoparafinov olefinami [Sulfuric Acid Alkylation of Isoparaffins with Olefins]. Moscow, Nauka Publ., 1970. 216 p. [in Russian].

12. Lavrenov A.V., Bogdanets E.N., Duplyakin V.K. Kataliz v promyshlennosti - Catalyst in Undustry, 2009, No. 1, pp. 28. [in Russian].

13. Querini C.A., Roa E. Deactivation of Solid Acid Catalysts During Isobutane Alkylation with $\mathrm{C}_{4}$ Olefins. Appl. Catal. A: Gen., 1997, Vol. 163, pp. 199.

14. Shuraev M.V., Krymkin N.Yu., Shakun V.A. Alkilirovanie izobutana butilenom $\mathrm{v}$ ravnovesnykh usloviyakh [Alkylation of Isobutane with Butylene under Equilibrium Conditions] Izvestiya Samarskogo nauchnogo tsentra Rossiiskoi akademii nauk - Proceedings of the Samara Scientific Center of the Russian Academy of Sciences, 2011, Vol. 1, No. 4 (4), pp. 1178-1182. [in Russian].

15. Zhang W., Sun İ., Prins R. The Journal of Physical Chemistry A., 2002, Vol. 106, 11805 p.

16. Pater J., Gardona F., Canaff C., Gnop N.S., Szabo G., Guisnet M. Alkylation of Isobutane with 2-Betene over HFAU Zeolite. Composition of Coke and Deactivation Effect. Industrial and Engineering Chemistry, 1999, No. 38, pp. 3822-3829.

17. Froment G.F. Stud. Surf. Sci. Catal., 1980, No. 6, pp. 1. 
18. Reyniers M.-F., Beirnaert H., Marin G.B. Influence of Coke Formation on the Conversion of Hydrocarbons I. Alkanes on a USY-Zeolite. Appl. Catal. A-Gen., 2000, No. 202 (1), pp. 49-63.

19. Reyniers M.-F., Tang Y., Marin G.B. Appl. Catal. A-Gen., 2000, No. 2 , pp. 65 .

20. Guisnet M., Magnoux P., Martin D. Stud. Surf. Sci. Catal., 1997, No. 111, pp. 1.

21. Hopkins P.D., Miller J.T., Meyers B.L., Ray G.J., Roginski R.T., Kuehne M.A., Kung H.H. Appl. Catal. A-Gen., 1996, No. 136, pp. 29.

22. Williams B.A., Babitz S.M., Miller J.T., Snurr R.Q., Kung H.H. Appl. Catal. A-Gen.,1999, No. 177, pp. 161.

23. Minachev Kh.M., Mortikov E.S., Zen'kovskii S.M., Mostovoi N.V., Kononov N.F. Alkilirovanie. Issledovanie i promyshlennoe oformlenie protsessa [Alkylation. Research and Industrial Design of the Process]. Moscow, Khimiya Publ., 1982, pp. 81-86. [in Russian].

24. Raseev S. Thermal and Catalytic Processes in Petroleum Refining. Marcel Dekker, New York, 2003. 920 p.

25. Hommeltoft S.I., Topsoe H.F.A. Alkylation Process. Patent USA, No. 5245100, 1993.

26. Hommeltoft S.I., Topsoe H.F.A. Alkylation Process. Patent USA, No. 5675053, 1997.

27. Mukherjee M., Nehlsen J. Reduce Alkylate Costs with Solid-Acid Catalysts. Hydrocarbon Processing. 2007.

28. Mukherjee M., Nehlsen J., Sundaresan S. Scale-Up Strategy Applied to Solid-Acid Alkylation Process. Oil and Gas J., 2006, No. 26, Vol. 104.

29. Mukherjee M., Nehlsen J., Dixon J., Suciu G.D. Step-Out Paraffin Alkylation Process Using Engineered Solid Catalyst. Hydrocarbon World, 2008, No. 1, Vol. 3.

30. Agrawal A., Balasubramanian K. Consider Catalyst Developments for Alkylation Production. Hydrocarbon Processing, 2006. 
31. Roeseler C.M., Black S.M., Shields D.J., Gosling C.D. Improved Solid Catalyst Alkylation Technology for Clean Fuels. The Alkylene Process. NPRA.

\section{Сведения об авторах}

\section{About the authors}

Трапезникова Е.Ф., канд. техн. наук, доцент кафедры «Газохимия и моделирование химико-технологических процессов», ФГБОУ $\mathrm{BO}$ «УГНТУ», г. Уфа, Российская Федерация

Trapeznikova E.F., Candidate of Engineering Sciences, Assistant Professor of Gas Chemistry and Modeling of Chemical Processes Department, FSBEI HE «USPTU», Ufa, Russian Federation

e-mail: elnik80@mail.ru

Смольникова Т.В., канд. хим. наук, доцент кафедры «Газохимия и моделирование химико-технологических процессов», ФГБОУ $\mathrm{BO}$ «УГНТУ», г. Уфа, Российская Федерация

Smolnikova T.V., Candidate of Chemical Sciences, Assistant Professor of Gas Chemistry and Modeling of Chemical Processes Department, FSBEI HE «USPTU», Ufa, Russian Federation

e-mail: chebaeva@mail.ru

Хафизова С.Р., канд. хим. наук, доцент кафедры «Газохимия и моделирование химико-технологических процессов», ФГБОУ ВО «УГНТУ», г. Уфа, Российская Федерация

Khafizova S.R., Candidate of Chemical Sciences, Assistant Professor of Gas Chemistry and Modeling of Chemical Processes Department, FSBEI HE «USPTU», Ufa, Russian Federation

e-mail: hafizovs@yandex.ru 
Николаева Т.В., магистрант кафедры «Газохимия и моделирование химико-технологических процессов», ФГБОУ ВО «УГНТУ», г. Уфа, Российская Федерация

Nikolaeva T.V., Undergraduate Student of Gas Chemistry and Modeling of Chemical Processes Department, FSBEI HE «USPTU», Ufa, Russian Federation e-mail: tanyniko@mail.ru

Нурисламова Р.Р., студент кафедры «Газохимия и моделирование химико-технологических процессов», ФГБОУ ВО «УГНТУ», г. Уфа, Российская Федерация

Nurislamova R.R., Student of Gas Chemistry and Modeling of Chemical Processes Department, FSBEI HE «USPTU», Ufa, Russian Federation e-mail: RimmaNurislamova1995@yandex.ru 